\title{
Formonsella pyramidosa (Haptophyta, Papposphaeraceae): a new weakly calcified coccolithophore genus from warm-water regions
}

\author{
Helge A. Thomsen ${ }^{1 *}$, Lluïsa $\operatorname{Cros}^{2}$, Elisa Malinverno ${ }^{3}$, Jette B. Østergaard ${ }^{4}$, \\ Mara Y. Cortés ${ }^{5}$, Markus Geisen ${ }^{6}$ \& Jeremy R. Young ${ }^{7}$ \\ ${ }^{1}$ Technical university of Denmark, National Institute of Aquatic Resources (DTU Aqua), Jægersborg Allé 1, \\ 2920 Charlottenlund, Denmark \\ 2 Institut de Ciències del Mar (CSIC), Passeig Marítim de la Barceloneta, 37-49, 08003 Barcelona, Spain \\ ${ }^{3}$ Department of Earth and Environmental Sciences (DISAT), University of Milano-Bicocca, Milano, Italy \\ ${ }^{4}$ Nørrebrogade 52a 5th, 2200 Copenhagen N, Denmark \\ ${ }^{5}$ Departamento Académico de Geología Marina, AICM UABCS, México \\ ${ }^{6}$ Diepeschrather Str. 6a, 51069 Köln, Germany \\ ${ }^{7}$ Department of Earth Sciences, University College London, Gower Street, London WC1E 6BT, UK \\ *Correspondence: hat@aqua.dtu.dk
}

\begin{abstract}
A new species Formonsella pyramidosa gen. et sp. nov. is described to accommodate a widely distributed warmwater coccolithophore species that has previously been referred to as Pappomonas sp. 2. Formonsella differs from Pappomonas with respect to, in particular, the detailed structure of the rim on both calicate and non-calicate coccoliths. In Formonsella the rim comprises two cycles of rod-shaped elements. Although elements in the distal layer are higher at one end, giving this cycle a serrate outline, the overall appearance is very different from the Pappomonas rim which encompasses a distal cycle of pentagonal elements, giving the rim a very distinct toothed appearance. Inverted rectangular pyramidal structures terminate the calicate $F$. pyramidosa coccoliths. In non-calicate coccoliths the central area calcification comprises differently sized tileshaped elements, mostly arranged along the longitudinal axis in a rather irregular way.
\end{abstract}

Keywords: coccolithophore, Papposphaeraceae, Formonsella gen. nov., SEM, TEM

Received 24 June 2015; accepted 11 September 2015

The core taxa of the Papposphaeraceae, with the exception of two generic types (Papposphaera lepida Tangen, 1972, and Pappomonas flabellifera Manton \& Oates, 1975), were initially described from Arctic and Antarctic sites (e.g. Manton \& Oates 1975; Manton et al. 1976a, b, 1977; Thomsen 1980a, b, c, d, 1981; Thomsen et al. 1988). However, weakly calcified coccolithophores affiliated with the Papposphaeraceae (Jordan \& Young 1990) have also been found on a number of occasions outside the polar regions (Thomsen \& Buck 1998; Cros \& Fortuño 2002; Malinverno et al. 2008; Andruleit \& Young 2010; Cortés, Thomsen, Young \& Østergaard unpublished observations).

Efforts have been made recently (Thomsen et al. 2013, 2016a, b; Thomsen \& Østergaard 2014a, b, 2015a, b) to revisit the polar contingent of weakly calcified coccolithophores while utilizing a large source of previously unpublished material, and with the purpose of updating and completing the taxonomic framework to the maximum extent possible without access to molecular data. The clarification achieved (or in process) with reference to the definition of the most prominent heterococcolithophore genera, i.e. Papposphaera Tangen, 1972 and Pappomonas Manton \& Oates, 1975 , now renders possible a more formal taxonomic description of the wealth of lightly calcified warm-water taxa that have been temporarily referred to as, for example, Pappomonas sp. types 1-5 and Papposphaera sp. types 1-5 (Cros 2001, unpublished PhD thesis, University of Barcelona; Cros \& Fortuño 2002; Young et al. 2003). In a recent paper (Thomsen et al. 2015), we described, based on material from Thailand coastal waters and the NW Mediterranean area, a new monotypic genus (Ventimolina stellata gen. et sp. nov.) that was previously referred to as 'unidentified sp. 2' by Cros \& Fortuño (2002). Here we describe, based on material from a number of warm-water sites that are widely separated geographically, a second monotypic genus (Formonsella pyramidosa gen. et sp. nov.) that was previously known as Pappomonas sp. type 2 (Cros \& Fortuño 2002).

\section{Material and methods}

The origin of the $F$. pyramidosa material utilized here and the sampling details are given in Table 1. For further details on the Andaman Sea sampling strategy, hydrography and lower trophic level communities, see Nielsen et al. (2004). Details concerning the Pacific Ocean NOAA Spring Cruise to the Equatorial Pacific are reported by Murray et al. (1994) and Chavez et al. (1996), for example.

The preparation for SEM involved in all cases a concentration of material on filters, usually of polycarbonate $(0.8 \mu \mathrm{m}$ pore diameter $)$ or cellulose acetate $(0.45 \mu \mathrm{m}$ pore size), followed by a thorough rinsing of the material to remove salt crystals using small amounts of bottled water, filtered tap water or distilled water. Cut-out pieces of the filters were sputter-coated with gold or gold-palladium to avoid charging and examined in a Philips XL-30 FEG SEM at the Natural History Museum, London (Fig. 1: 1-3; Fig. 3: 3-5), a Cambridge Stereoscan at the University of Milan (Fig. 2: 1, 4), a Hitachi S-2300 at the Universidad Autónoma de Baja California Sur (Fig. 2:3) and a Hitachi S-570 or S-3500 SEM at the Institut Ciències del Mar, Barcelona (Fig. 2: 2, 5, 6; Fig. 3: 1, 2, 6, 7).

Nannoplanktonic organisms intended for transmission electron microscope (TEM) analysis were selected by prefiltration (mesh size $20 \mu \mathrm{m}$ ) and concentrated by means of gravity filtration on top of a $2.0 \mu \mathrm{m}$ Millipore filter. The sample volume was $0.5-21$. Organisms collected on the filter were gently resuspended in a small volume of 


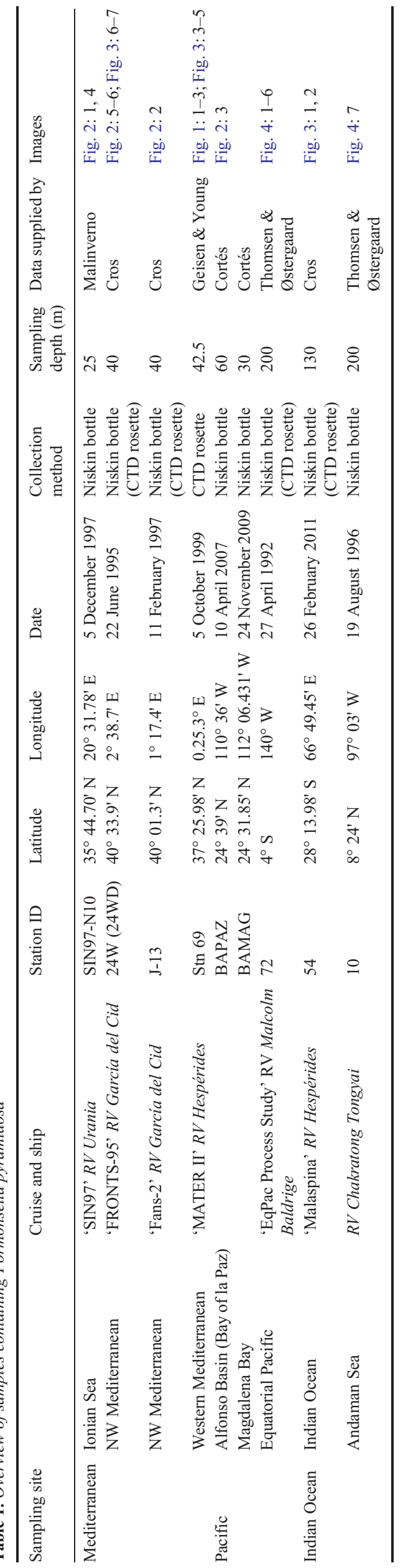

seawater and further concentrated by means of centrifugation. Whole mounts for examination in a TEM were prepared from the resuspended pellet of material according to well-established procedures (Moestrup \& Thomsen 1980). The TEM grids were shadow cast with chromium at a low angle and examined in a JEM100SX electron microscope at the Botanical Institute, University of Copenhagen.

The terminology used follows Young et al. (1997, 2003).

\section{Systematic descriptions}

Division Haptophyta Hibberd, 1972

Class Prymnesiophyceae Hibberd, 1976

Family incertae sedis Papposphaeraceae Jordan \& Young, 1990; Andruleit \& Young, 2010 emend.

Formonsella gen. nov.

Type species. Formonsella pyramidosa sp. nov.

Derivation of name. Formonsa (L) (equal to formosa) meaning beautiful and 'ella' diminutive.

Diagnosis. Coccosphere dimorphic comprising muroliths with and without central structures. The rim calcification comprises two cycles of rod-shaped elements; elements in the distal cycle vary in height from one end to the other, giving the entire cycle a serrated distal margin. The two coccolith types form separate parts of the coccosphere.

Comments. The species described here as a monotypic genus has been previously referred to as Pappomonas sp. 2 (Cros 2001, unpublished $\mathrm{PhD}$ thesis, University of Barcelona; Cros \& Fortuño 2002; Young et al. 2003) because of the dimorphic muroliths where one type has a central spine that is reminiscent of structures described from species of Pappomonas. However, critical differences, in particular with respect to the details of the rim structure in coccoliths of Formonsella when compared with Pappomonas spp., clearly emphasize the need for a new genus to accommodate our new taxon. In species of Pappomonas (Thomsen \& Østergaard $2014 b$ ) the rim is constructed from a proximal cycle of rod-shaped elements and a distal cycle of pentagonal elements, giving the rim a toothed appearance. This is markedly different from the two cycles of quasi-similar rod-shaped elements that is a characteristic feature of Formonsella. It should also be emphasized that the genus Pappomonas as currently defined (Thomsen \& Østergaard 2014b) is characterized by a two-dimensional calyx structure in contrast to the three-dimensional calyx types that are typical of species of Papposphaera and also Formonsella gen. nov.

\section{Formonsella pyramidosa sp. nov.}

(Figs 1-4)

Diagnosis. The coccosphere measures c. $9 \mu \mathrm{m}$ in diameter. The inner cell diameter is $c .4 \mu \mathrm{m}$.

Non-calicate coccoliths are narrowly elliptical (c. $0.6 \times 1.1 \mu \mathrm{m})$. Central area calcification is limited to a single layer of differently sized tile-shaped elements. There is often a peripheral cycle of elements lined up approximately along the rim and sometimes this pattern continues towards the centre. In the middle part of the central area the elements are in other coccoliths roughly longitudinal, with some elements randomly oblique to transversal. The rim is formed by two cycles of rod-shaped elements. Elements from the proximal cycle are fairly symmetrical along all axes. Elements from the distal cycle are lower at the anticlockwise end (distal view), thus giving a series of elements an appearance similar to roofing tiles. The junctions of two distal cycle elements are offset with respect to similar junctions in the proximal cycle. 

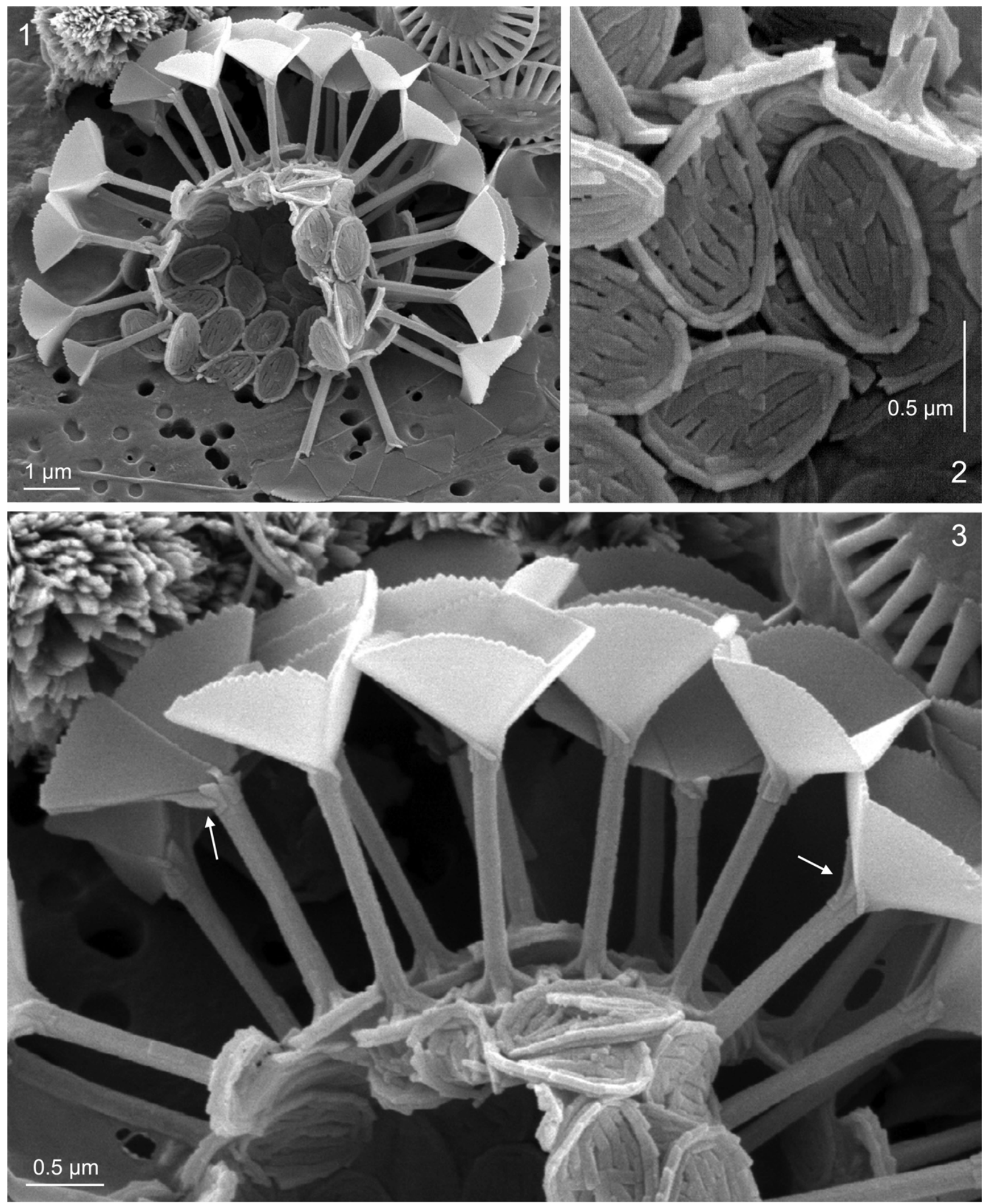

Fig. 1. Formonsella pyramidosa (holotype): SEM micrographs of material from the Alboran Sea, Western Mediterranean. (1) Complete coccosphere showing the two types of coccoliths. (2) Detail from (1) of non-calicate coccoliths. Notice the central area tiles and the two-layered rim with a serrated distal outline. Calicate coccoliths are seen in side view in the upper part of the image. (3) Detail from (1) showing calicate spines in two lines exposing the longest axes of the rectangular pyramids. The axial cross leading into the stem is visible in several coccoliths. The finely serrate and convex margins of the inverted pyramid are evident, as is also the buttresses supporting the proximal part of the inverted pyramid (arrows).

Calicate coccoliths occur in a distinct band of mostly double rows of coccoliths. The individual coccolith is nearly circular in outline and c. $0.75 \mu \mathrm{m}$ in diameter. A cross-shaped central area calcification leads into a hollow stem which ranges in length from 1.4 to $1.7 \mu \mathrm{m}$.
The calyx is formed by four triangular plates that are pairwise differently sized and united to form an inverted, rectangular pyramidal shape. The upper edge of each triangular plate is convex and finely serrate. A wristlet-like structure is present at the base of 

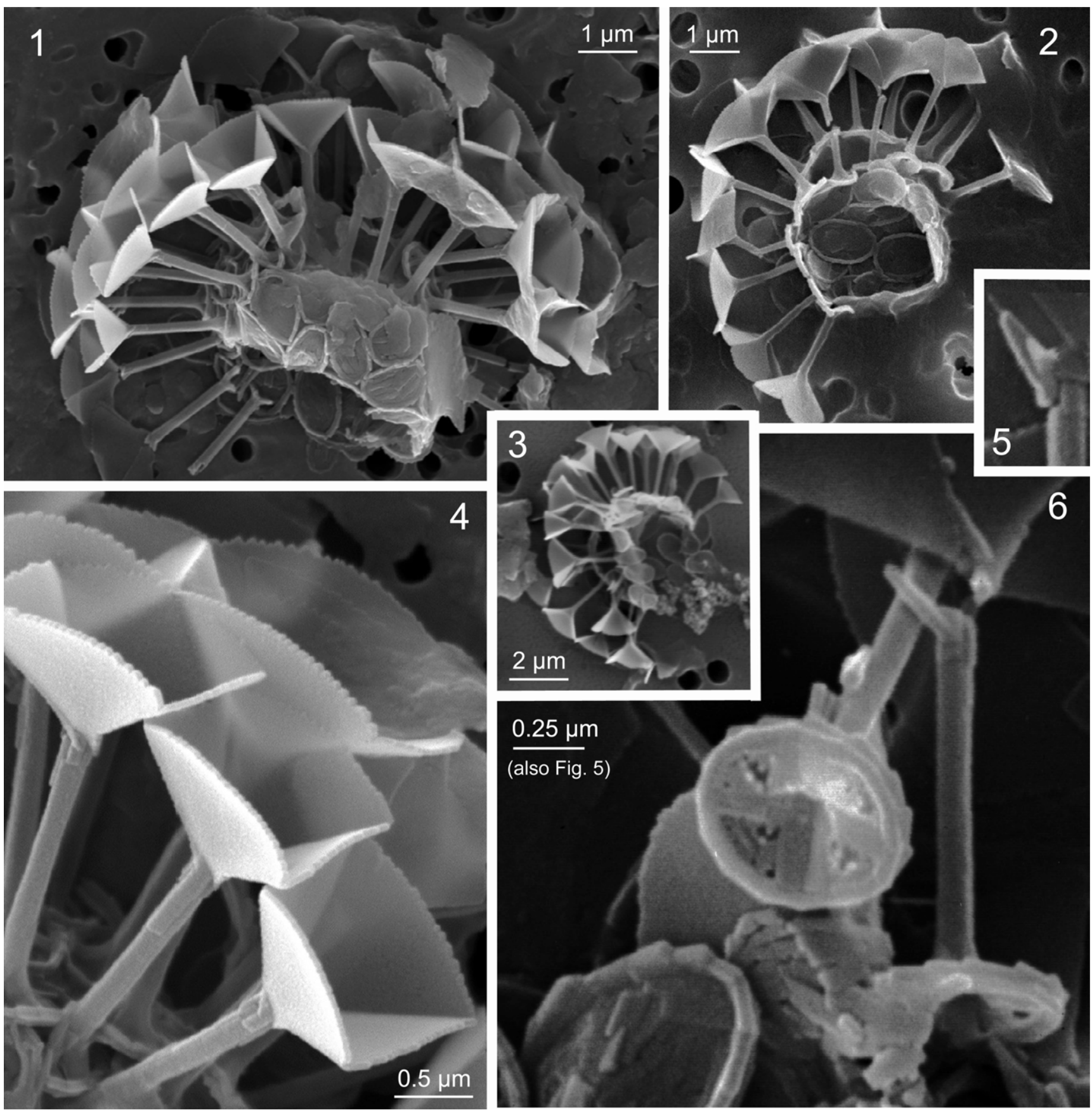

Fig. 2. SEM images of Formonsella pyramidosa from the Ionian Sea (1, 4), the northwestern Mediterranean $(2,5,6)$ and the Gulf of California (3). (1-3) Complete coccospheres showing patches of similar coccoliths. (4) Detail of calyx structure in calicate coccoliths from the coccosphere shown in (1). The wristlet-like structure and the buttresses are less well defined in comparison with the type material (see Fig. 1:3). Notice the regular appearance of the calicate coccoliths in two rows. (5) Buttress arising from a supporting platelet. (6) Detail of calicate coccolith showing the proximal face of the coccolith. The axial cross stands out clearly, as does also the serrate distal margin of the rim. The distal face of a non-calicate coccolith is partly shown in the lower left corner of the image. A ribbed free buttress is evident on a non-tilted calicate coccolith.

the inverted pyramid. The coccolith rim is basically similar to that described above for the non-calicate coccoliths. The main difference is a more pronounced vertical extension of elements from both cycles and particularly those from the distal cycle.

Holotype. Figure 1: 1-3 (same cell).

Holotype sample. West Mediterranean, Alboran Sea (MATER II stn. $69 / 11 ; 37.43^{\circ} \mathrm{N}, 0.42^{\circ} \mathrm{E}$ ). The sample was collected 5 October 1999 at a depth of $42.5 \mathrm{~m}$.

Holotype depository. The Natural History Museum, London image reference $193 / 86$ to $193 / 90$.
Derivation of name. From pyramidos (L) meaning pyramid.

Description - coccospheres. The material of $F$. pyramidosa illustrated here, in addition to the Mediterranean (Alboran Sea) type material (Fig. 1: 1-3), originates from the same area (Fig. 3: 3-5) but also from widely separated geographical localities from within the circum global warm-water belt (Fig. 2: 1, 4, Eastern Mediterranean, Ionian Sea; Fig. 2: 3, Gulf of California; Fig. 2: 2, 5 , 6 and Fig. 3: 6, 7, northwestern Mediterranean; Fig. 4: 1-6, Tropical Pacific Ocean; Fig. 3: 1, 2, Indian Ocean; Fig. 4: 7, Indian Ocean, Andaman Sea). It is obvious when scrutinizing the images that there is limited morphological and dimensional variability across the 

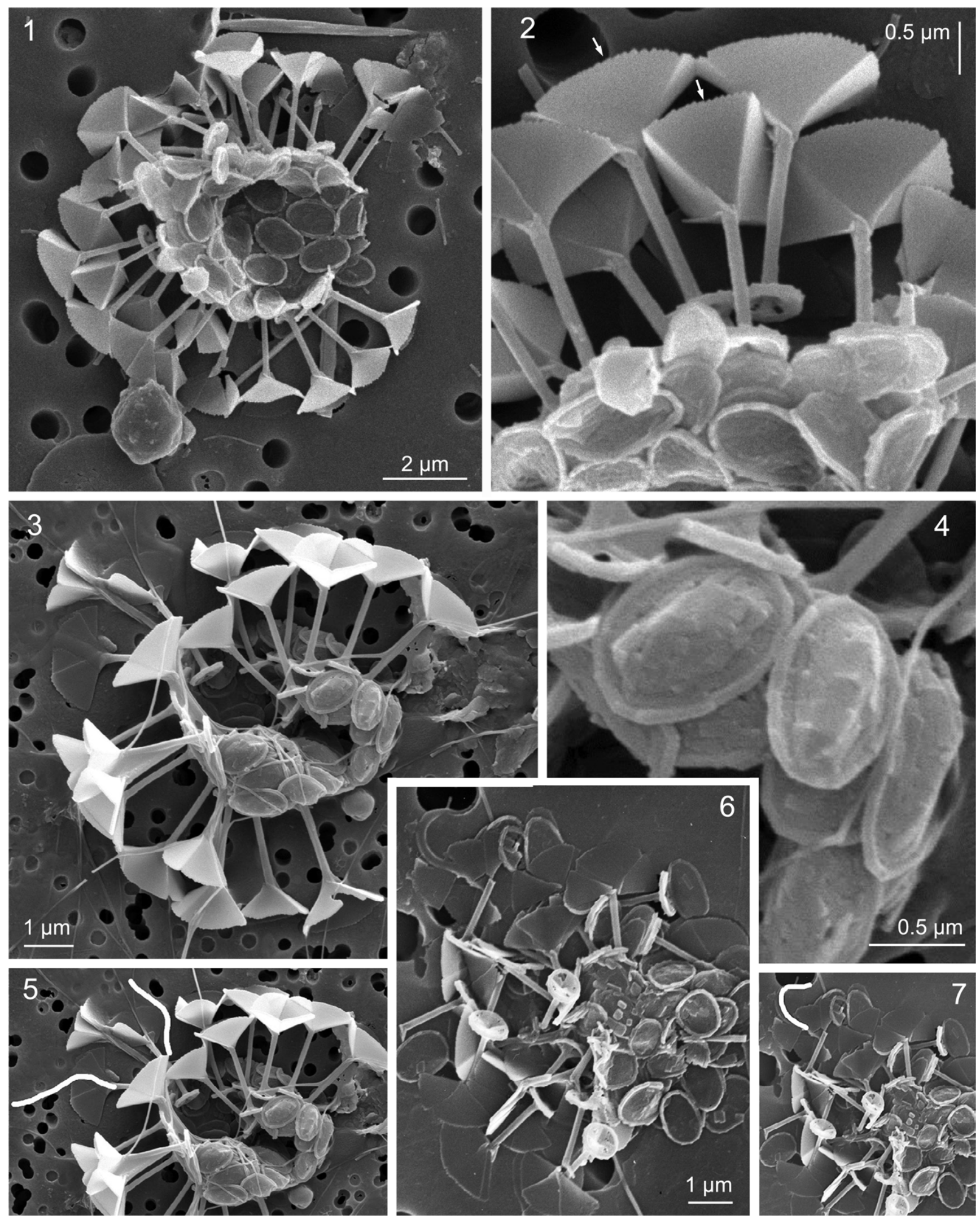

6

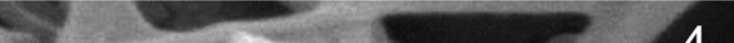

Fig. 3. SEM images of Formonsella pyramidosa from the Indian Ocean (1, 2), from the Alboran Sea (3-5) and from the northwestern Mediterranean $(6,7)$. (1) Complete coccosphere showing the patchy occurrence of the two types of coccoliths. In this particular cell it is easy to visualize the calicate coccoliths as an equatorial band separating hemispheres of non-calicate coccoliths. (2) Detail from (1) of calicate coccoliths clearly displaying differences in edge length among opposite pairs of triangles (arrows). (3) Complete coccosphere with flagella (see (5) for positions). (4) Detail of non-calicate coccoliths from (3) showing the central mound. (5) Position of flagella in (3), here traced in white. (6) Coccosphere with presumptive flagellum (see (7) for position).

(7) Position of flagella in (6), here traced in white. 


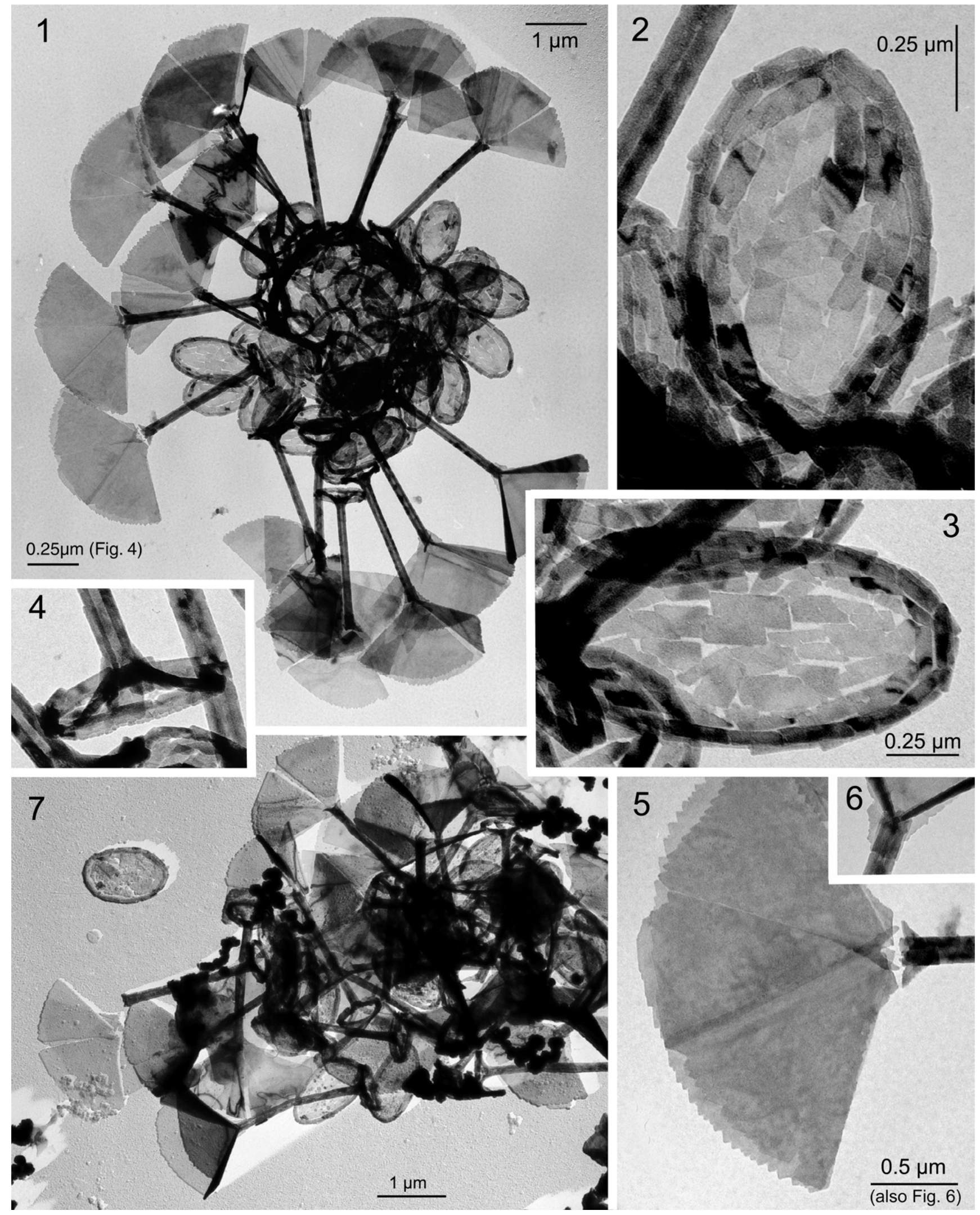

Fig. 4. TEM images of material from the Equatorial Pacific (1-6) and the Andaman Sea, Indian Ocean (7). (1) Complete coccosphere. $(\mathbf{2}, \mathbf{3})$ Details of noncalicate coccoliths from the coccosphere shown in (1). (4) Detail of the proximal part of a calicate coccolith showing the continuation of the arms of the axial cross into the stern and the hollowness of this. (5) Detail of a collapsed inverted pyramid displaying on top two markedly differently sized triangular blades. Notice also the unevenly serrate upper margin. (6) Detail of weakly developed buttress and the wristlet-like structure. (7) Scatter of coccoliths.

geographical range sampled. Table 2 summarizes dimensional characteristics.

There is reason to add only a few additional observations to the rather detailed species diagnosis.
We were initially inclined to believe that the calyx was a symmetrical inverted pyramid, although it was evident that the pyramids in, for example, Figure 1: 3; Figure 2: 4 seemed to have two opposite somewhat shorter edges, giving the pyramid a 
rectangular footprint. In as much as this might be just a depth-related illusion we were at first hesitant to accept the rectangular footprint, until finding the cell illustrated in Figure 3: 1, 2. In this particular coccosphere one coccolith is obviously tilted $90^{\circ}$ in comparison with its neighbouring coccoliths and clearly displaying within the same focal depth a significantly shorter edge to the pyramid.

In general it seems to be the case that calicate coccoliths form fairly regular bands in which the individual coccoliths line up in double rows exposing the longest profile of the individual calyx (Fig. 1: 3; Fig. 2: 4; Fig. 3: 2). It is interesting to notice that the extended stretch with double rows is typically terminated by short sequences with single coccoliths. There are different options with respect to interpreting the positioning of the calicate coccoliths within the coccosphere. One possibility is that these are equatorially distributed with the non-calicate coccoliths occurring both on the upper cell surface (i.e. facing toward the observer) and on the lower cell surface (collapsing on to the filter). Notice that in every specimen available to us the equatorial belt of calicate coccoliths is incomplete. A second option is that the belt of calicate coccoliths encircles a rather large flagellar opening. The evidence for this is currently limited. However, we have observed Mediterranean cells that appear to be flagellated (Fig. 3: 3, 6) and, in those cases, the occurrence of the 'flagella' relative to the calicate coccoliths is at least consistent with an interpretation of the belt representing a circum-flagellar array of coccoliths. In accordance with this interpretation the single coccoliths terminally positioned in the belt may represent the result of a tearing apart of a complete double belt of coccoliths as a result of mechanical disturbance to the coccosphere during filtration and drying.

An area of particular interest is the transition in calicate coccoliths from the stem to the calyx. It is evident here that the walls of the inverted pyramid are supported proximally at the junctions between neighbouring triangles by buttresses. These are particularly evident in Figure 1: 3 (arrows) where the individual buttress is seen to arise from a rectangular plate that is firmly attached to the stem, but also visible in Figure 2: 4-6 and Figure 4: 1. The wristlet-like structure referred to in the diagnosis is, in this species, in fact a constituent part of this supportive structure at the base of each of the triangular blades, i.e. the attachment plates for each of the four buttresses.

In general the non-calicate coccoliths tend to appear very much identical across the geographical sites sampled. However, some non-calicate coccoliths (Fig. 3: 3,4) have a distinctly raised distal surface (a central mound) whilst in most other specimens they look more or less flat. The relevance of this finding is not clear for the moment. It may represent a capacity for significant variability within the species, an indication of exothecal coccoliths in Formonsella, or it might just conceivably indicate a different species. So long as the specimens available of $F$. pyramidosa are largely restricted to those illustrated here, it is premature to conclude anything based on this isolated observation.

The details provided in the species diagnosis with reference to the fine structure of the coccolith rim is corroborated by material from other geographical sources (see, for example, Fig. 2: 6). The TEM micrographs nicely resolve details with regard to central area calcification in non-calicate coccoliths (Fig. 4: 2, 3) and the hollowness of the stem in calicate coccoliths (Fig. 4: 4).

\section{Discussion}

The description of $F$. pyramidosa is preliminary in the sense that we are, for example, not convincingly capable of demonstrating whether this species is a typical haptophyte and furnished with two flagella and a haptonema. In flagellated coccolithophore cells there is always a distinct polarity of the cell which is also typically reflected in a consistent distribution of coccolith types across the cell surface. In flagellated papposphaeraceans (e.g. Pappomonas spp.) 
calicate coccoliths are typically found as circum-flagellar coccoliths and in a smaller version as antapical coccoliths, whereas the remaining cell surface supports the non-calicate body coccoliths (Thomsen \& Østergaard 2014b). The demonstration of possible flagellation in Formonsella opens up an interpretation of the double band of calicate coccoliths as representing, in fact, circum-flagellar coccoliths - yet with a large flagellar opening - and with the noncalicate coccoliths occupying the remaining parts of the surface area, which thus puts Formonsella in alignment with key members of the Papposphaeraceae (e.g. Pappomonas spp. and Papposphaera spp.).

However, a second option needs to be discussed with respect to the possible positioning within the coccosphere of the belt of calicate spines. These may, in fact, be equatorial and with noncalicate coccoliths occurring on both hemispheres of the cell. If this interpretation is correct it leaves room at least for comparisons between Formonsella and, for example, Solisphaera (Bollmann et al. 2006), in which coccoliths with distinct features form a circular ring, or corona, around the coccosphere. Despite the likely similarity in the positioning of such a conspicuous array of coccoliths, we are not convinced that this similarity (if at all relevant) is evidence for phylogenetic affinity but rather a case of adaptive convergence.

We need to emphasize that at present we are not aware of a life cycle counterpart of $F$. pyramidosa. The presence or absence of chloroplasts in $F$. pyramidosa also remains unknown. While papposphaeraceans in general are known to be non-photosynthetic (Marchant \& Thomsen 1994) within their main realms, the polar regions, it is for the moment unclear whether this also applies to their warm-water relatives such as $F$. pyramidosa.

A final negative observation that we need to make here for the sake of completeness is the absence of non-mineralized underlayer scales in F. pyramidosa. In a TEM micrograph such as Figure 4: 1 with an unobstructed view of multiple open spaces between coccoliths one would expect that unmineralized underlayer scales, if present, would be visible.

Very little information can currently be extracted with respect to the ecology of $F$. pyramidosa. However, when scrutinizing the characteristics of water samples yielding $F$. pyramidosa it becomes evident that this organism has a preference for deep water (lower photic zone) and offshore habitats (100-200 m). The known depth range for the organism is at present $25-200 \mathrm{~m}$. However, in coastal Mexican waters (Alfonso Basin and off Magdalena Bay) $F$. pyramidosa is most frequently found at fairly shallow depths between 30 and $45 \mathrm{~m}$ and at a preferred water temperature of $16^{\circ} \mathrm{C}$ (Alfonso Basin) and $19^{\circ} \mathrm{C}$ (Magdalena Bay).

\section{Acknowledgements and Funding}

Thanks are due to crew members and scientific personnel participating in the research cruises that supplied material for this publication. Thanks to JoséManuel Fortuño for operating the SEM in Barcelona, and Marta Estrada and the Malaspina Project for kindly providing samples. Thanks also to Agostino Rizzi for operating the SEM in Milan, and to Karla Sidón, who was collecting part of the material and operating the SEM for the Mexican Alfonso Basin samples.

\section{Scientific editing by Emanuela Mattioli}

\section{References}

Andruleit, H. \& Young, J.R. 2010. Kataspinifera baumannii: A new genus and species of deep photic coccolithophores resembling the non-calcifying haptophyte Chrysochromulina. Journal of Micropalaeontology, 29, 135-147.

Bollmann, J., Cortés, M.Y., Kleijne, A., Østergaard, J.B. \& Young, J. 2006. Solisphaera gen. nov. (Prymnesiophyceae), a new coccolithophore genus from the lower photic zone. Phycologia, 45, 465-477.

Chavez, F.P., Buck, K.R., Service, S.K., Newton, J. \& Barber, R.T. 1996. Phytoplankton variability in the central and eastern tropical Pacific. Deep-Sea Research II, 43, 835-870.

Cros, L. \& Fortuño, J.-M. 2002. Atlas of the northwestern Mediterranean coccolithophores. Scientia Marina, 66(Suppl. 1), 1-186.

Hibberd, D.J. 1972. Chrysophyta: Definition and interpretation. British Phycological Journal, 7, 281.
Hibberd, D.J. 1976. The ultrastructure and taxonomy of the Chrysophyceae and Prymnesiophyceae (Haptophyceae): A survey with some new observations on the ultrastructure of the Chrysophyceae. Botanical Journal of the Linnean Society, 72, 55-80.

Jordan, R.W. \& Young, J.R. 1990. Proposed changes to the classification system of living coccolithophorids. International Nannoplankton Association Newsletter, 12, 15-18.

Malinverno, E., Dimiza, M.D., Triantaphyllou, M.V., Dermitzakis, M.D. \&

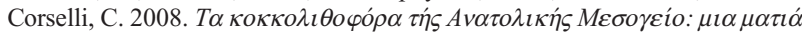

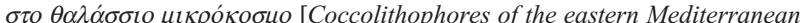
Sea: A look into the marine micro world]/I coccolitoforidi del Mar Mediterraneo orientale: uno sguardo nel microcosmo marino. ION Publications, Athens, Greece.

Manton, I. \& Oates, K. 1975. Fine-structural observations on Papposphaera Tangen from the Southern Hemisphere and on Pappomonas gen. nov. from South Africa and Greenland. British Phycological Journal, 10, 93-109.

Manton, I., Sutherland, J. \& McCully, M. 1976a. Fine structural observations on coccolithophorids from South Alaska in the genera Papposphaera Tangen and Pappomonas Manton et Oates. British Phycological Journal, 11, 225-238.

Manton, I., Sutherland, J. \& Oates, K. 1976b. Arctic coccolithophorids: Two species of Turrisphaera gen. nov. from West Greenland, Alaska and the Northwest Passage. Proceedings Royal Society London, Series B, 194, 179-194.

Manton, I., Sutherland, J. \& Oates, K. 1977. Arctic coccolithophorids: Wigwamma arctica gen. et sp. nov. from Greenland and arctic Canada, W. annulifera sp. nov. from South Africa and S. Alaska. Proceedings Royal Society London, Series B, 197, 145-168.

Marchant, H.J. \& Thomsen, H.A. 1994. Haptophytes in polar waters. In: Green, J.C. \& Leadbeater, B.S.C. (eds) The Haptophyte Algae. Systematics Association Special Volume 51. Clarendon Press, Oxford, 209-228.

Moestrup, Ø.\& Thomsen, H.A. 1980. Preparation of shadow-cast whole mounts. In: Gantt, E. (ed.) Handbook of Phycological Methods, Vol. III. Cambridge University Press, Cambridge, 385-390.

Murray, J.W., Barber, R.T., Roman, M.R., Bacon, M.P. \& Feely, R.A. 1994 Physical and biological controls on carbon cycling in the equatorial. Pacific Science, 266, 58-65.

Nielsen, T.G., Bjørnsen, P.K. et al. 2004. Hydrography, bacteria and protist communities across the continental shelf and shelf slope of the Andaman Sea (NE Indian Ocean). Marine Ecology Progress Series, 274, 69-86.

Tangen, K. 1972. Papposphaera lepida, gen. nov., n. sp., a new marine coccolithophorid from Norwegian coastal waters. Norwegian Journal of Botany, 19, 171-178.

Thomsen, H.A. 1980a. Two species of Trigonaspis gen. nov. (Prymnesiophyceae) from West Greenland. Phycologia, 19, 218-299.

Thomsen, H.A. 1980b. Turrispheara polybotrys sp. nov. (Prymnesiophyceae) from West Greenland. Journal of the Marine Biological Association of the United Kingdom, 60, 529-537.

Thomsen, H.A. 1980c. Wigwamma scenozonion sp. nov. (Prymnesiophyceae) from West Greenland. British Phycological Journal, 15, 335-342.

Thomsen, H.A. 1980d. Quaternariella obscura gen. et sp. nov. (Prymnesiophyceae) from West Greenland. Phycologia, 19, 260-265.

Thomsen, H.A. 1981. Identification by electron microscopy of nanoplanktonic coccolithophorids (Prymnesiophyceae) from West Greenland, including the description of Papposphaera sarion sp. nov. British Phycological Journal, 16, 77-94.

Thomsen, H.A. \& Buck, K.R. 1998. Nanoflagellates of East Pacific coastal waters: Morphology, taxonomy, and biogeography of weakly calcified coccolithophores (Haptophyceae, Prymnesiophyceae). Cryptogamie, Algologique, 19, 29-48.

Thomsen, H.A. \& Østergaard, J.B. 2014a. Cocolithophorids in polar waters: Calciarcus spp. revisited. Acta Protozoologica, 53, 145-157.

Thomsen, H.A. \& Østergaard, J.B. 2014b. Cocolithophorids in polar waters: Pappomonas spp. revisited. Acta Protozoologica, 53, 235-256.

Thomsen, H.A. \& Østergaard, J.B. 2015a. Cocolithophorids in polar waters: Trigonaspis spp. revisited. Acta Protozoologica, 54, 85-96.

Thomsen, H.A. \& Østergaard, J.B. 2015b. Coccolithophorids in polar waters: Mercedesia gen. nov., Ericiolus, Quaternariella and Porsildia gen.nov. Acta Protozoologica, 54, 155-169.

Thomsen, H.A., Buck, K.R., Coale, S.L., Garrison, D.L. \& Gowing, M.M. 1988. Nanoplanktonic coccolithophorids (Prymnesiophyceae, Haptophyceae) from the Weddell Sea, Antarctica. Nordic Journal of Botany, 8, 419-436.

Thomsen, H.A., Østergaard, J.B. \& Heldal, M. 2013. Coccolithophorids in polar waters: Wigwamma spp. revisited. Acta Protozoologica, 52, 237-256.

Thomsen, H.A., Østergaard, J.B. \& Cros, L. 2015. Ventimolina stellata gen. et sp. nov. (Haptophyta, Papposphaeraceae) from warm water regions. Acto Protozoolgica, 54, 275-281.

Thomsen, H.A., Heldal, M. \& Østergaard, J.B. 2016a. Coccolithophores in polar waters: Papposphaera sarion HET and HOL revisited. Micropaleontology, 61, 429-438.

Thomsen, H.A., Heldal, M. \& Østergaard, J.B. 2016b. Coccolithophores in polar waters: Papposphaera arctica HET and HOL. Micropaleontology, 61, 419-427.

Young, J.R., Bergen, J.A. et al. 1997. Guidelines for coccolith and calcareous nannofossil terminology. Palaeontology, 40, 875-912.

Young, J., Geisen, M., Cros, L., Kleijne, A., Sprengel, C., Probert, I. \& Østergaard, J. 2003. A guide to extant coccolithophore taxonomy. Journal of Nannopankton Research, Special Issue, 1, 1-132. 